\title{
Transmission and transparent wavelength conversion of an optically labeled signal
} using ASK/DPSK orthogonal modulation

\author{
Chi, Nan; Zhang, Jianfeng; Holm-Nielsen, Pablo Villanueva
}

Published in:

I E E E Photonics Technology Letters

Link to article, DOI:

10.1109/LPT.2003.809922

Publication date:

2003

Document Version

Publisher's PDF, also known as Version of record

Link back to DTU Orbit

Citation (APA):

Chi, N., Zhang, J., \& Holm-Nielsen, P. V. (2003). Transmission and transparent wavelength conversion of an optically labeled signal using ASK/DPSK orthogonal modulation. I E E E Photonics Technology Letters, 15(5), 760-762. https://doi.org/10.1109/LPT.2003.809922

\section{General rights}

Copyright and moral rights for the publications made accessible in the public portal are retained by the authors and/or other copyright owners and it is a condition of accessing publications that users recognise and abide by the legal requirements associated with these rights.

- Users may download and print one copy of any publication from the public portal for the purpose of private study or research.

- You may not further distribute the material or use it for any profit-making activity or commercial gain

- You may freely distribute the URL identifying the publication in the public portal 


\title{
Transmission and Transparent Wavelength Conversion of an Optically Labeled Signal Using ASK/DPSK Orthogonal Modulation
}

\author{
Nan Chi, Jianfeng Zhang, Pablo V. Holm-Nielsen, Christophe Peucheret, and Palle Jeppesen, Member, IEEE
}

\begin{abstract}
We report an experimental investigation of transmission and transparent wavelength conversion properties of a two-level optically labeled signal using amplitude-shift-keying/differential-phase-shift-keying orthogonal modulation. Error-free transmission of a 10-Gb/s payload and $2.5-\mathrm{Gb} / \mathrm{s}$ label over $80-\mathrm{km}$ nonzero dispersion-shifted fiber is achieved with less than 1-dB power penalty. Transparent wavelength label swapping based on four-wave mixing in a highly nonlinear fiber is also demonstrated, clearly validating this orthogonal modulation scheme as a potential solution for optical labeling.
\end{abstract}

Index Terms-Four-wave mixing (FWM), optical labeling, optical packet switching, wavelength conversion.

\section{INTRODUCTION}

$\mathbf{T}$ HE FUTURE ultrahigh-speed data-centric network will evolve into an Internet protocol (IP) network on a wavelength-division-multiplexing (WDM) physical infrastructure [1]. The use of optical labels to route and forward IP data without having to detect the payload is, therefore, essential to overcome the electronics bottlenecks [2]. In addition to the optical wavelength that can serve as an optical label in multiprotocol $\lambda$ switching schemes, a second level of optical label is still necessary for provisioning, maintaining, and restoring switched light-paths. This second level optical label can be realized by subcarrier multiplexing (SCM) [2], [3] or by using orthogonal modulation format [4]-[8] combining amplitude shift keying (ASK) and differential phase-shift keying (DPSK) on a single carrier.

In this letter, we present transmission and all-optical wavelength label swapping experiments for an optically labeled signal using ASK/DPSK orthogonal modulation format. Simultaneous error-free transmission of the 10-Gb/s ASK payload and the $2.5-\mathrm{Gb} / \mathrm{s}$ DPSK label is obtained over $80-\mathrm{km}$ nonzero dispersion-shifted fiber (NZDSF) with less than 1-dB power penalty. Wavelength label swapping which preserves the DPSK label is also demonstrated in a highly nonlinear fiber (HNLF) based on the four-wave mixing (FWM) process. The successful transmission and wavelength conversion suggest the potential applications of the orthogonal modulation scheme in future IP-over-WDM networks using optical labeling techniques.

Manuscript received October 14, 2002; revised December 27, 2002. This work was supported in part by the European Commission under the IST STOLAS (Switching Technologies for Optically Labeled Signals) Project.

The authors are with the COM Center, Technical University of Denmark, Lyngby DK-2800, Denmark (e-mail: nc@com.dtu.dk).

Digital Object Identifier 10.1109/LPT.2003.809922

\section{TRANSMISSION EXPERIMENT}

The ASK/DPSK scheme carries the optical label in-band on the same wavelength as the payload. Fig. 1 shows the setup of the transmission experiment. The signal source is a wavelength tunable external cavity laser (ECL) working at $1555.7 \mathrm{~nm}$. The signal is first-intensity modulated at $10 \mathrm{~Gb} / \mathrm{s}$ by a Mach-Zehnder modulator (MZM). The 2.5-Gb/s DPSK label is then impressed by the subsequent phase modulator. The ASK payload and DPSK label are not synchronized in this case. The transmission span consists of 80-km NZDSF with dispersion of $4.8 \mathrm{ps} / \mathrm{nm} / \mathrm{km}$ and dispersion slope of $0.044 \mathrm{ps} / \mathrm{nm}^{2} / \mathrm{km}$. A matching length of dispersion compensating fiber (DCF) is used to fully compensate the chromatic dispersion in the NZDSF in order to get good receiver sensitivity for both the payload and label. It should be noted that the dispersion tolerance of the ASK/DPSK is also important for system evaluation and this will be investigated in our future work. At the receiver, the DPSK label information can be recovered by simply adding a one-bit delay Mach-Zehnder interferometer before direct detection [6], thus avoiding the coherent detection and notch filters that are in general usage in the SCM scheme [2], [3].

In order to detect the DPSK label, a limited extinction ratio (ER) of the payload is necessary [7]. An increase of the ER will result in better transmission performance of the ASK payload but cause a detrimental effect on the DPSK label and vice versa. It is, therefore, essential to optimize the ER of the transmitter. The measured back-to-back receiver sensitivities of the payload and the label as a function of the payload ER are shown in Fig. 2. As expected, we observe a tradeoff between the ER requirements for the payload and the label. Since an error in the label will lead the whole packet to a wrong address, the label performance is more critical than the performance of the payload. Therefore, we choose an ER equal to $3 \mathrm{~dB}$ such that the receiver sensitivity of the label is about $3 \mathrm{~dB}$ better than that of the payload. This requirement is also in accordance with [6], where a more strict BER of $10^{-12}$ is required for the label.

The BER performance and the eye diagrams of the payload and label after transmission over 80-km NZDSF with precompensation scheme are measured as illustrated in Fig. 3. Very clear and open eyes can be obtained for both the payload and the label after transmission. Because of the influence of the ASK payload, we observe a splitting of the " 0 " level and "1" level for the demodulated DPSK label [7]. Both the payload and the label can be obtained error-free after $80-\mathrm{km}$ transmission. The DPSK label shows a low power penalty of $0.5 \mathrm{~dB}$. The receiver 


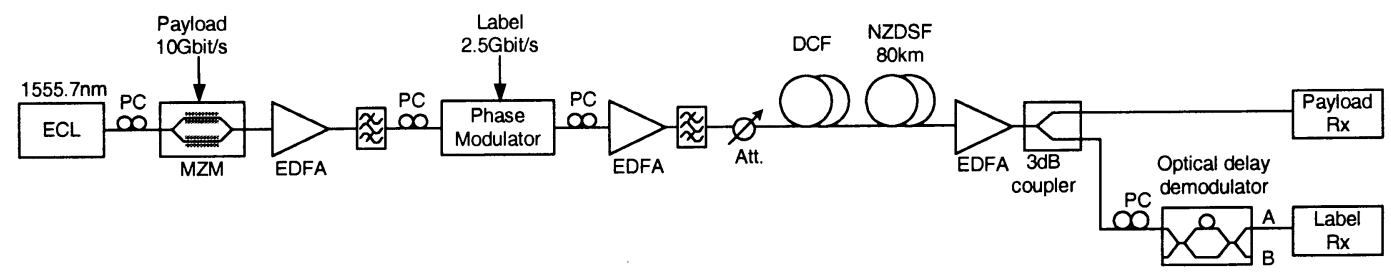

Fig. 1. Experimental setup. PC: polarization controller. Att.: attenuator.

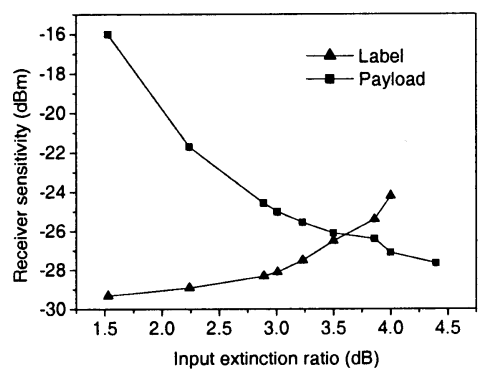

Fig. 2. Measured back-to-back receiver sensitivity versus payload ER for the label and the payload.

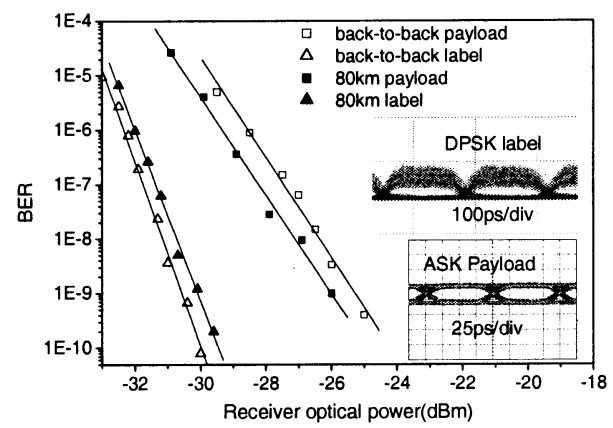

Fig. 3. Measured BER performance for back-to-back and after 80-km NZDSF transmission and eye diagrams of the payload and label after transmission.

sensitivity of the payload after transmission is observed to be even enhanced by $0.7 \mathrm{~dB}$ compared to the back-to-back case, because the pulses are significantly broadened after the DCF due to the self-phase modulation but the following NZDSF acts on the chirped pulse to compress them to a width narrower than they were initially. Compared to our earlier experimental transmission of the ASK/DPSK packets over 50-km SMF [8], the usage of NZDSF provides a considerable improvement. It was also tried to place the DCF after the NZDSF in a postcompensation scheme; that lead to $1.5-\mathrm{dB}$ penalty for the payload sensitivity while the same label sensitivity relatively to the precompensation scheme was maintained.

\section{TRANSPARENT WAVELENGTH CONVERSION}

The optical labels are deployed to build up an appropriate optical path in the transmission fiber network and can be swapped in the network intermediate nodes. To realize wavelength label swapping of this ASK/DPSK modulated signal while preserving the DPSK label, as for instance in core routers, interferometric devices based on cross-phase modulation in SOAs cannot be applied, and instead some transparent wavelength conversion scheme must be considered to preserve

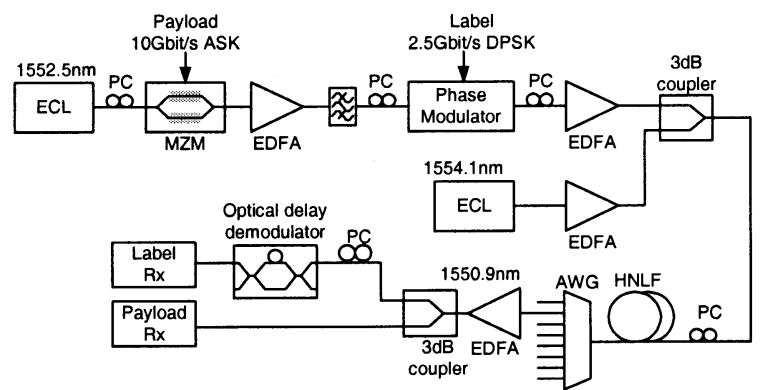

Fig. 4. Experimental setup. PC: polarization controller.

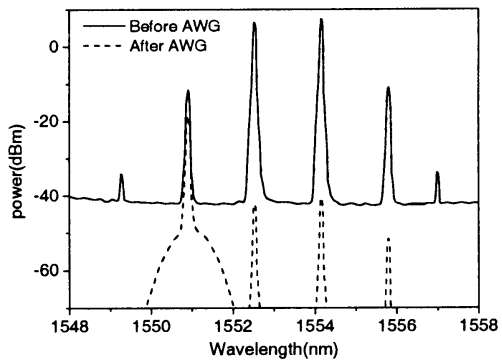

Fig. 5. Optical spectra at the output of 500-m HNLF (solid line) and the filtered converted signal after the AWG.

the phase information. By using FWM in fibers, it is possible to implement a modulation transparent wavelength converter [9]. Recent FWM wavelength conversion experiments [9] also indicate that using HNLF can result in large spectral and dynamic ranges. Therefore, wavelength conversion using HNLF can be chosen as an ideal solution to transparent wavelength label swapping for the combined ASK/DPSK signal.

The experimental setup is shown in Fig. 4. The pump and signal sources are ECLs working at 1554.1 and $1552.5 \mathrm{~nm}$, respectively. The ASK/DPSK signal is amplified and combined with the pump after polarization alignment. FWM takes place in the 500-m-long HNLF with a nonlinear coefficient $\gamma=10.6 \mathrm{~W}^{-1} \mathrm{~km}^{-1}$. The zero dispersion wavelength of the HNLF is $1553.6 \mathrm{~nm}$ and the dispersion slope is $0.022 \mathrm{ps} / \mathrm{nm}^{2} / \mathrm{km}$. An arrayed waveguide grating (AWG) with channel spacing of $200 \mathrm{GHz}$ is used to filter out the converted signal. Fig. 5 shows the optical spectra at the output of the HNLF and the converted signal after the AWG. A wide detuning range $(>10 \mathrm{~nm})$ of the pump wavelength is observed in this setup provided the input signal power is $18 \mathrm{dBm}$. When the detuning is fixed to $1.6 \mathrm{~nm}$, the input dynamic power range is from 6.3 to $18 \mathrm{dBm}$. By optimizing the states of polarization of the pump and signal and the input power dynamic range, a conversion efficiency of the FWM process up to $-15 \mathrm{~dB}$ could be achieved. 


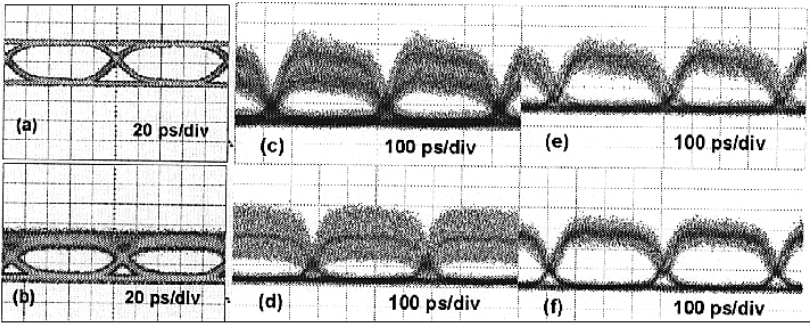

Fig. 6. Measured eye diagrams of (a) back-to-back payload, (b) converted payload, (c) back-to-back label, (d) converted label, (e) back-to-back DPSK signal without ASK modulation, and (f) converted DPSK signal without ASK modulation.

The converted signal is then split into two parts by a 3-dB coupler and received by the payload receiver and the label receiver; thereby, the BER performance of payload and label are measured simultaneously. The original (back-to-back) eye diagrams of the payload and the label are shown in Fig. 6(a) and (c).

Because the FWM effect in fibers can be exploited to achieve all-optical reshaping [10], it can be predicted that the ER of the converted ASK signal at $1550.9 \mathrm{~nm}$ will be enhanced due to this reshaping characteristics. This is verified in our experiment. When the ASK signal has an initial ER of $3 \mathrm{~dB}$, the ER of the converted signal is measured to be $3.5 \mathrm{~dB}$. Therefore, if the label performance is still demanded to outperform the payload, according to the previous discussion of the optimization of the input ER, a lower ER of less than $3 \mathrm{~dB}$ should be selected. In our experiment, the ER of the input signal is set to $2.8 \mathrm{~dB}$.

After FWM wavelength conversion, the phase information of the input signal is well replicated onto the new wavelength. The converted label has clearly multilevels but has reduced amplitude fluctuation in the "marks" as compared to the back-to-back label (see Fig. 6). We believe this can also be ascribed to the reshaping of the ASK signal. In our setup, a Bessel low-pass electrical filter with the usual $70 \%$ bit rate bandwidth was not applied in the receiver. However, it can be envisaged that such a Bessel filter would be very beneficial for both payload and label detection due to the reduction of the noise variance with acceptable intersymbol interference. Power penalty of the label is measured relative to the back-to-back case and found to be smaller than $1.6 \mathrm{~dB}$. However due to the noise imposed in the "mark" of the ASK payload and the low ER, the power penalty of the payload is about $5 \mathrm{~dB}$. The BER performance of the DPSK signal for back-to-back and wavelength conversion are also measured when the payload is switched off as shown in Fig. 7. In this case, the power penalty is within $1 \mathrm{~dB}$ and a very low receiver sensitivity of $-36.5 \mathrm{dBm}$ is obtained.

A similar FWM product at $1555.8 \mathrm{~nm}$, namely the idler, was also tried to be detected. However in our experiment, error-free operation for both the payload and label could not be achieved with this product. We believe this is because the reshaping effect would not take place with this FWM product [9].

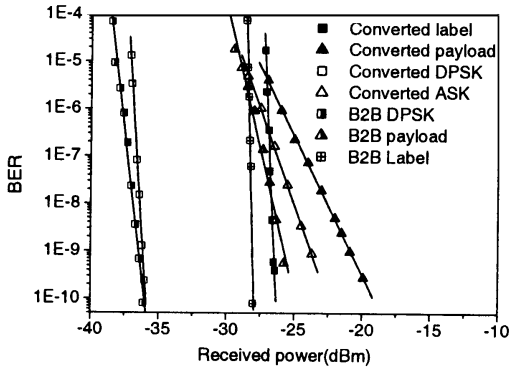

Fig. 7. Measured BER performance for the payload and the label back-to-back and after FWM wavelength conversion.

\section{CONCLUSION}

We have presented an experimental investigation of transmission performance as well as all-optical transparent wavelength conversion of an optically labeled signal using ASK/DPSK orthogonal modulation format. The penalties of the payload and label after transmission in 80-km NZDSF are both below $1 \mathrm{~dB}$. Wavelength label swapping and DPSK label replication by employing FWM in an HNLF is also demonstrated. The experimental results suggest that the orthogonal ASK/DPSK modulation scheme could be a promising candidate for optical labeling in future IP-over-WDM networks.

\section{ACKNOWLEDGMENT}

The authors would like to thank Dr. S. Nissen Knudsen, with OFS Denmark, for having supplied the HNLF.

\section{REFERENCES}

[1] N. Ghani, "Lambda-labeling: A framework for IP-over-WDM using MPLS," Opt. Networks Mag., vol. 1, no. 2, pp. 45-58, 2000.

[2] D. J. Blumental et al., "All-optical label swapping networks and technologies," J. Lightwave Technol., vol. 18, pp. 2058-2075, Dec. 2000.

[3] B. Meagher et al., "Design and implementation of ultra-low latency optical label switching for packet-switched WDM networks," J. Lightwave Technol., vol. 18, pp. 1978-1987, Dec. 2000.

[4] M. Hickey, C. Barry, C. Noronha, and L. Kazovsky, "Experimental PSK/ASK transceiver for the STARNET WDM computer communication network," IEEE Photon. Technol. Lett., vol. 5, pp. 568-571, May 1993.

[5] T. Koonen, G. Morthier, J. Jennen, H. Waardt, and P. Demeester, "Optical packet routing in IP-over-WDM networks deploying two-level optical labeling," in Proc. ECOC'01, 2001, pp. 14-15.

[6] T. Koonen, S. Sulur, I. Monroy, J. Jennen, and H. Waardt, "Optical labeling of packets in IP-over-WDM networks," presented at the ECOC'02, Copenhagen, Country, 2002, Paper 5.5.2.

[7] N. Chi, B. Carlsson, P. V. Holm-Nielsen, C. Peucheret, and P. Jeppesen, "Dispersion management for two-level optically labeled signals in IP-over-WDM networks," presented at the ECOC'02, Copenhagen, Denmark, 2002, Paper 5.5.1.

[8] N. Chi, B. Carlsson, J. Zhang, P. V. Holm-Nielsen, C. Peucheret, and P. Jeppesen, "Transmission performance of all-optically labeled packets using ASK/DPSK orthogonal modulation," presented at the LEOS'02, Glasgow, U.K., 2002, Paper MF3.

[9] M. Westlund, J. Hansryd, P. A. Andrekson, and S. N. Knudsen, "Transparent wavelength conversion in fiber with $24 \mathrm{~nm}$ pump tuning range," Electron. Lett., vol. 38, no. 2, pp. 85-86, 2002.

[10] E. Ciaramella, F. Curti, and S. Trillo, "All-optical signal reshaping by means of four-wave mixing in optical fibers," IEEE Photon. Technol. Lett., vol. 13, pp. 142-144, Feb. 2001. 